\title{
Influence of multiple scattering on CloudSat measurements in snow:
} A model study

\author{
Sergey Y. Matrosov ${ }^{1}$ and Alessandro Battaglia ${ }^{2}$ \\ Received 15 April 2009; revised 9 May 2009; accepted 27 May 2009; published 18 June 2009.
}

[1] The effects of multiple scattering on larger precipitating hydrometers have an influence on measurements of the spaceborne W-band (94 GHz) CloudSat radar. This study presents initial quantitative estimates of these effects in "dry" snow using radiative transfer calculations for appropriate snowfall models. It is shown that these effects become significant (i.e., greater than approximately $1 \mathrm{~dB}$ ) when snowfall radar reflectivity factors are greater than about 10-15 dBZ. Reflectivity enhancement due to multiple scattering can reach 4-5 dB in heavier stratiform snowfalls. Multiple scattering effects counteract signal attenuation, so the observed CloudSat reflectivity factors in snowfall could be relatively close to the values that would be observed in the case of single scattering and the absence of attenuation. Citation: Matrosov, S. Y., and A. Battaglia (2009), Influence of multiple scattering on CloudSat measurements in snow: A model study, Geophys. Res. Lett., 36, L12806, doi:10.1029/2009GL038704.

\section{Introduction}

[2] The satellite-borne W-band (94 GHz) nadir-pointing cloud profiling radar (CPR) onboard CloudSat [Tanelli et $a l ., 2008]$ has been successfully operating since 2006. While the main objective of this radar is to acquire the information on clouds, it also resolves many precipitation systems. The CloudSat measurements have been used for rainfall retrievals [e.g., Matrosov, 2007a; Haynes et al., 2009] and some initial snowfall retrievals [e.g., Matrosov et al., 2008a; Liu, 2008].

[3] The measurements from CloudSat are profiles of the radar reflectivity factor, $Z_{e}$, (hereafter "reflectivity"). For ground-based and airborne W-band radars, an assumption of single scattering (SS) for interpreting reflectivity measurements is generally valid. However, a large CPR footprint $(\sim 1.5 \mathrm{~km})$ results in multiple scattering (MS) contributions that enhance reflectivity [Battaglia and Simmer, 2008]. For rainfall, MS effects become significant when rain rates, $R$, are greater than about $1-2 \mathrm{~mm} \mathrm{~h}^{-1}$, although vertical gradients of $Z_{e}$ do not exhibit significant sensitivity to these effects unless $R>5 \mathrm{~mm} \mathrm{~h}^{-1}$ or so [Matrosov et al., 2008b].

[4] MS increases as hydrometeor characteristic sizes and extinction increase. While it is the strongest in liquid and mixed hydrometeor phases, one can expect certain MS

\footnotetext{
${ }^{1}$ Cooperative Institute for Research in Environmental Sciences, University of Colorado and NOAA Earth System Research Laboratory, Boulder, Colorado, USA.

${ }^{2}$ Meteorological Institute, University of Bonn, Bonn, Germany.

Copyright 2009 by the American Geophysical Union. 0094-8276/09/2009GL038704
}

effects present in the CloudSat measurements in snowfall and also in the ice parts of precipitating cloud systems with reflectivity values similar to those of snowfall near the ground [e.g., Matrosov and Heymsfield, 2008]. Some comparisons of satellite-based and airborne W-band radar data indicate MS effects in CloudSat reflectivities from such systems [e.g., Bouniol et al., 2008].

[5] CloudSat-based retrieval schemes currently use the SS assumption for deriving parameters of ice hydrometeors. Ignoring MS effects can result in some retrieval biases for snowfall and ice parts of precipitating clouds. The objective of this study is to evaluate the magnitude of MS effects in snow and thick ice clouds using model calculations. The current modeling is concerned with "dry" snow/ice, the term which is used for describing conditions with small amounts of supercooled water and crystal riming. Such conditions often exist in stratiform precipitating systems.

\section{Snowfall Model and the Calculation Method}

[6] Snowflake size distributions (SSDs) are usually described by the exponential function which is defined by the intercept $N_{0}$ and the slope parameter $\Lambda$. Experimental data [Braham, 1990; Woods et al., 2008] show that at temperatures $-5^{\circ} \mathrm{C}-0^{\circ} \mathrm{C}, N_{0}$ usually changes between about 0.2 and $1 \mathrm{~cm}^{-4}$, and $\Lambda$ changes between about 10 and $30 \mathrm{~cm}^{-1}$. The correlation between these two SSD parameters is rather weak [Braham, 1990]. These changes in $N_{0}$ and $\Lambda$ represent the range of SSD parameters observed in field experiments and correspond to changes in liquid equivalent snowfall rate from about 0.1 to $27 \mathrm{~mm} \mathrm{~h}^{-1}$.

[7] Both $N_{0}$ and $\Lambda$ change with height. Woods et al. [2008] present linear fits of observed $\Lambda$ values as a function of temperature. There is a gradual increase in $\Lambda$ as temperature decreases. Under assumption that the temperature dependence is a proxy for the changes of the $\Lambda$ parameter with height within a given vertical profile, the following height dependence of $\Lambda$ can be suggested

$$
\Lambda(h)=\Lambda(0)(1+h),
$$

where $h$ is the height in $\mathrm{km}$ above the reference level 0 corresponding to the surface (for ground snowfall) or the freezing level, when ground air temperatures are above freezing. Equation (1) is in general agreement with experimental data from [Woods et al., 2008, Figure 5] for cold-type snowfalls which indicate a factor of about 4 increase in $\Lambda$ when temperature decreases from $-5^{\circ} \mathrm{C}$ to $-30^{\circ} \mathrm{C}$. It corresponds to about a $3 \mathrm{~km}$ height difference for a temperature gradient of about $-8^{\circ} \mathrm{C} \mathrm{km}^{-1}$.

[8] For a given snowfall profile, the parameter $N_{0}$ increases with height at lower altitudes. Profile vertical 


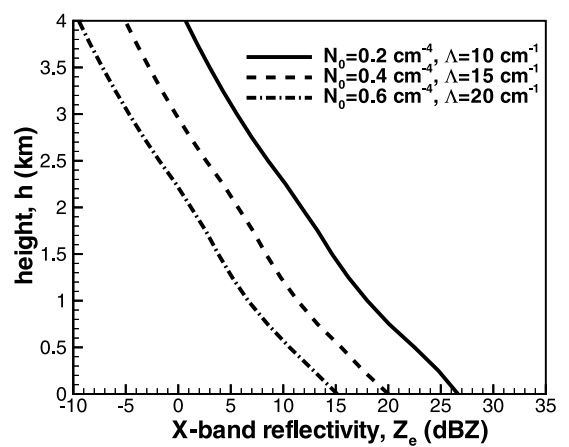

Figure 1. Representative model vertical profiles of nonattenuated X-band reflectivities.

changes are governed by the processes of particles growth as they descend. Two main mechanisms, which are responsible for the growth, are vapor deposition and aggregation. Mitchell [1988] suggests that the aggregation process is dominant in a $1-2 \mathrm{~km}$ thick zone. He showed that in this zone

$$
N_{0} \sim \Lambda^{\mathrm{b}},
$$

where $b=2.1 \pm 0.2$. The vapor deposition process dominates at higher altitudes, where the particle concentrations remain approximately constant (i.e., $N_{0}=$ const).

[9] In the adopted snowflake profile model, it was assumed that the aggregation growth zone is $1 \mathrm{~km}$ thick and extends from the surface (or from the freezing level for the precipitating systems resulting in rainfall at the ground). The vapor deposition growth zone is separated by the aggregation growth zone by a transition zone, which is also $1 \mathrm{~km}$ thick. The value of $b$ in the transition zone was interpolated from 2.1 at the top of the aggregation growth zone to 0 at the bottom of the vapor deposition zone.

[10] This study adopted the snowflake mass - size relations from [Matrosov, 2007b] used for modeling mmwavelength radar reflectivities of snowfall. These relations define the size dependent densities of snowflakes. The spheroidal model with an aspect ratio of 0.6 for aggregate snowflakes was assumed. Such aspect ratios are commonly observed in situ [Korolev and Isaac, 2003] and the spheroidal shape satisfactorily describes the observed dualwavelength radar ratios, which could not be explained by a spherical shape model [Matrosov et al., 2005]. A temperature gradient of $-8^{\circ} \mathrm{C} \mathrm{km}^{-1}$ and the lowest height temperature of $-2^{\circ} \mathrm{C}$ were also assumed.

[11] Figure 1 shows modeling results of non-attenuated SS reflectivities at X-band $(9.4 \mathrm{GHz})$ for three pairs of representative lowest height (i.e., $h=0 \mathrm{~km}$ ) values of $N_{0}$ and $\Lambda$. At X-band, attenuation in dry snowfall is negligible and the SS profiles approximate observed reflectivities. These model results are similar to X-band profiles observed above the freezing level in stratiform systems [Matrosov et al., 2007]. For such systems, when melting snowfall results in surface rainfall up to $10-15 \mathrm{~mm} \mathrm{~h}^{-\mathrm{P}}$, typical vertical gradients of observed X-band values of $Z_{e}$, are around 5$6 \mathrm{dBkm}^{-1}$, which is in general agreement with the model results. The correspondence between modeled and observed absolute values and vertical gradients of X-band reflectivity is an indirect indication of the general robustness of the described model.

[12] The Monte-Carlo method [Battaglia et al., 2006] was used for modeling CloudSat reflectivities. This method was previously used to assess MS effects in rainfall for CloudSat rainfall retrievals [Matrosov et al., 2008b]. Comparisons of this method with other methods showed its robustness [Battaglia et al., 2008a]. The previous studies with this method [e.g., Battaglia et al., 2008b] were focused primarily on MS effects in CloudSat rainfall measurements, and ice parts of precipitating systems were treated simplistically (e.g., height independent exponential SSDs and a constant snowflake density assumption). In this study, realistic size dependent snowflake densities and vertical profiles of SSDs covering a wide range of experimentally observed SSD parameters are considered.

[13] Twenty five model snowfall profiles were constructed for estimating CloudSat MS effects in snowfall. Corresponding non-attenuated W-band reflectivity profiles are shown in Figure 2a, where the lowest level values of parameters $N_{0}$ and $\Lambda$ are also depicted. They cover the range of variability of these parameters. The lowest height level snowfall rates, $S$, are shown also. A fall velocity - size relation from [Mitchell and Heymsfield, 2005] was used for $S$ estimates. Presented model profiles might also be considered as characteristic for ice parts of stratiform precipitating systems when rainfall results from melting snow. Estimates of $S$ can be considered as a proxy of surface rain rates if a common assumption about a constancy of the flux in mixed-phase and liquid layers is made.

[14] In the general case of non-spherical particles, the scattering phase function should depend on four angles (the zenith and azimuth angles of the incident and scattered beams). In many practical cases, however, phase functions for spherical particles are used, which greatly simplifies calculations since these functions depend only on the scattering angle. Here phase functions for spheres that have the same mass and density as spheroidal particles (hereafter, soft sphere phase functions) and phase functions for spheres that have the same mass and solid ice density (hereafter, hard sphere phase functions) were used in two sets of calculations. In both cases, the original profiles of nonattenuated reflectivity and single scattering albedo for spheroidal assumption were retained while extinction profiles were tuned to the phase functions. Some justification for this phase function consideration is provided by Liu [2004], where it was concluded that the phase functions of non-spherical ice/snow particles fall between those of the hard and soft spheres.

\section{Modeling Results}

[15] Figures $2 b$ and $2 c$ show modeling results of the MS reflectivity profiles with accounting for attenuation for different phase function assumptions. The difference in MS reflectivities under the assumptions of soft and hard sphere phase functions is generally negligible and can be ignored for most practical cases. The results indicate that MS effects generally become noticeable (greater than a few tenths of $1 \mathrm{~dB}$ ) when $Z_{e}$ values are greater than about $10 \mathrm{dBZ}$. The strongest MS enhancement of CloudSat 

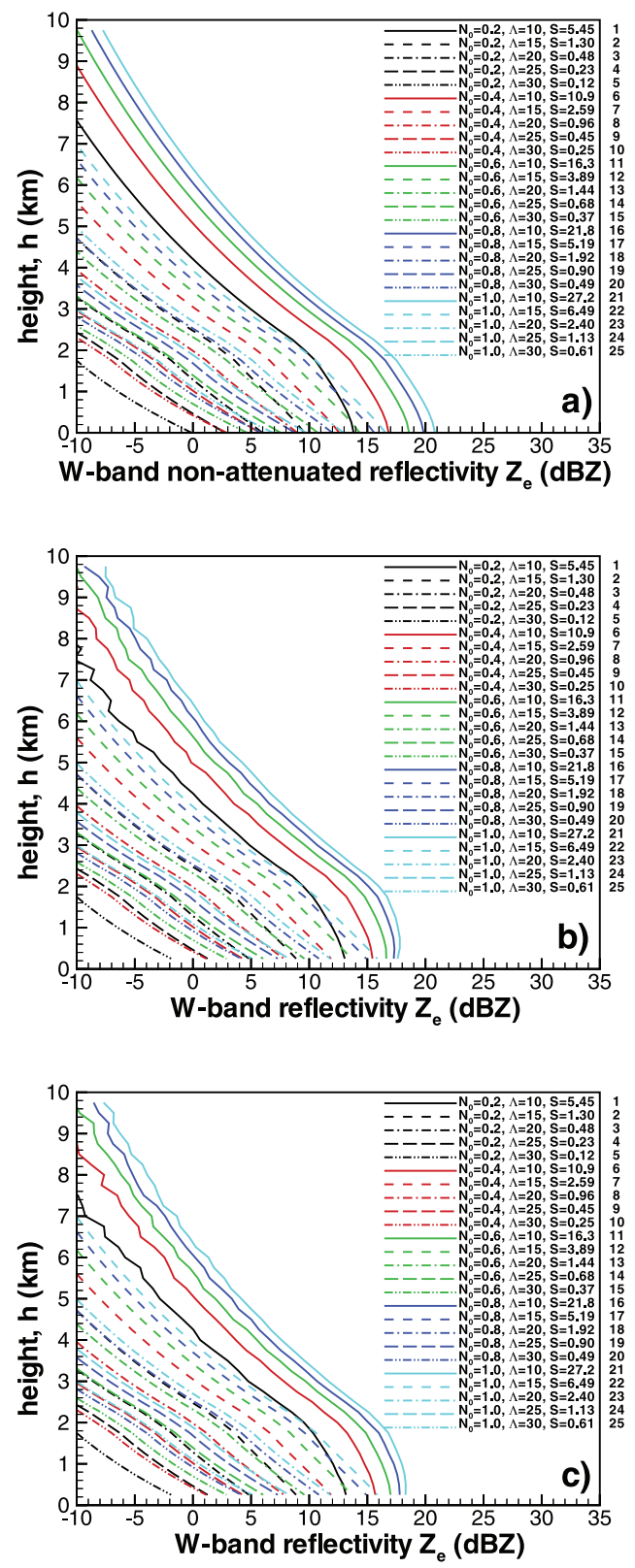

Figure 2. Model profiles of non-attenuated (a) W-band reflectivity and MS reflectivity profiles calculated with accounting for attenuation for (b) soft and (c) hard sphere phase function assumptions. Lowest level SSD parameters $\left(N_{0}\right.$ in $\mathrm{cm}^{-4}, \Lambda$ in $\left.\mathrm{cm}^{-1}\right)$ and liquid equivalent precipitation rates $\left(\mathrm{S}\right.$ in $\left.\mathrm{mmh}^{-1}\right)$ are also shown.

reflectivities can be expected for snowfalls with larger snowflakes (i.e., smaller $\Lambda$ ). $\Lambda$ values around $10 \mathrm{~cm}^{-1}$ are among the smallest exponential slope values observed in experimental SSDs [Braham, 1990]. For $\Lambda=10 \mathrm{~cm}^{-1}$, Figure 3 shows CloudSat reflectivity profiles at lower heights where MS effects become significant. Profiles are shown for a number of models with lowest height values of $N_{0}$, which result in precipitation rates in a range of about 5$16 \mathrm{mmh}^{-1}$. Such rates were observed in stratiform rainfall resulting from melting snow [e.g., Matrosov et al., 2007].

[16] While attenuation decreases CloudSat reflectivities compared to SS non-attenuated values, MS acts in the opposite direction. It can be seen from Figure $3 \mathrm{a}$ that MS enhancement effects can reach 3-4 dB. For heavier snowfalls (e.g., models 16 and 21 from Figure 2) this enhancement can be 5-6 dB (not shown). While such heavy snowfalls are uncommon for stratiform events, they might be not out of the question in the areas of convection. It should be mentioned that the MS results presented above do not include the effect of direct (i.e., $180^{\circ}$ ) backscatter enhancement which is not present in full amplitude in CloudSat measurements due to satellite movements (section $2 \mathrm{c}$ of Battaglia et al. [2008a]). This effect, which would be present for stationary platform radars, could reach about $2 \mathrm{~dB}$ for stronger MS effect cases from Figure 3.

[17] The MS enhancement partially offsets the reflectivity decrease due to attenuation. The net effect of MS and attenuation is still negative but not very great (in the absolute sense), thus the MS values of reflectivity (with accounting for attenuation) are smaller than those for nonattenuated SS reflectivity by not more than about $1-1.8 \mathrm{~dB}$ for the examples shown in Figure 3. It probably could be considered as an upper boundary estimate for stratiform dry snowfall. Heavier precipitation rates, as those represented by models 16 and $21\left(S>20 \mathrm{~mm} \mathrm{~h}^{-1}\right)$, are likely to be associated with convective systems. For these models, the lowest gate differences between the non-attenuated SS and MS reflectivities can reach 3-4 dB (not shown). Note that hard sphere phase function assumption produces less MS enhancements and less attenuation compared to the soft sphere phase function assumption (Figure $3 \mathrm{a}$ versus Figure $3 b$ ). The overall balance effects are, however, similar, so the difference between MS reflectivities and
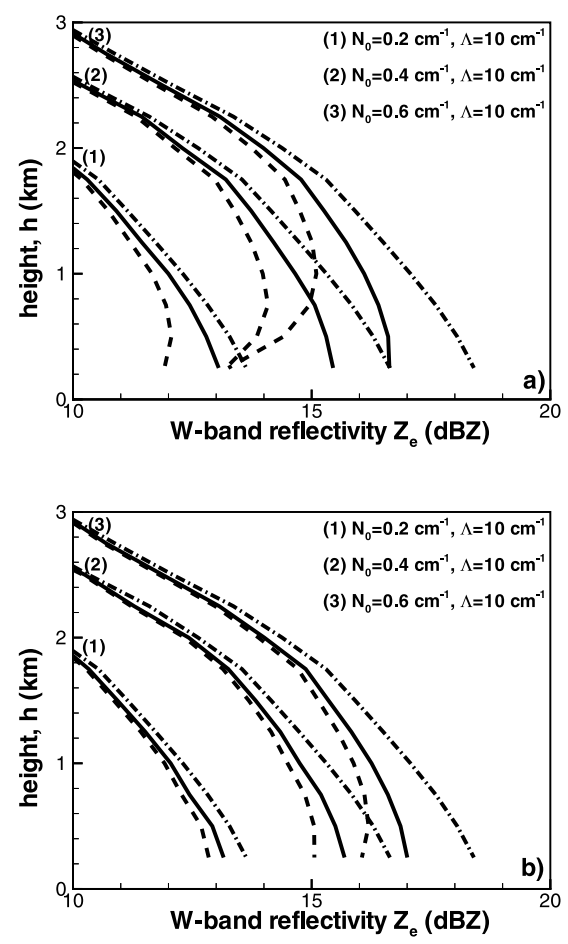

Figure 3. Model W-band reflectivity profiles calculated with accounting for MS and attenuation (solid), with accounting only for SS and attenuation (dashed), and nonattenuated SS reflectivites (dot-dashed) for (a) soft and (b) hard sphere phase functions. 
non-attenuated SS reflectivities is very comparable for both assumptions. As $\Lambda$ values increase, both the negative contributions of attenuation (in the absolute sense) and positive enhancements due to MS effects become smaller.

\section{Discussion and Conclusions}

[18] Bouniol et al. [2008] experimentally estimated MS effects in CloudSat data in thick ice anvils by comparing these data with approximately coincident measurements from an airborne W-band radar. They concluded that CPR echoes experienced MS effects with a magnitude of approximately $4.5 \mathrm{~dB}$. At the same time, there was about $4.7 \mathrm{~dB}$ of attenuation, so, at a level of their observations, where CloudSat observed reflectivities were about 15$16 \mathrm{dBZ}$, there was an approximate balance (i.e., a cancellation) of CPR signal enhancements due to MS effects and signal reduction due to attenuation. This experimental observation is in qualitative agreement with the results of modeling presented here, although the microphysical information on snow/ice particles in the anvil was not exactly known.

[19] One conclusion that can be drawn from the presented study is that ignoring both attenuation and MS effects might not be entirely counter productive when applying CloudSat retrieval techniques in snowfall and ice parts of stratiform precipitating systems. Accounting only for attenuation, however, might noticeably bias retrievals. While the net effect of MS and attenuation is expected to be slightly negative, the total underestimation of $Z_{e}$ (as compared to non-attenuated SS values), could be relatively small and reach $1-1.8 \mathrm{~dB}$ only for heavier stratiform precipitation. This could be is on the order of the uncertainty of CPR measurements. This total underestimation might be even further reduced because some part of the direct backscatter enhancement mentioned above may result in an additional increase of observed reflectivities.

[20] In a more vigorous approach, separate MS and attenuation corrections can be potentially developed as a function of reflectivity and the observation height. Such corrections would probably be more important for precipitation containing significantly rimed particles (e.g., graupel). In this case, attenuation and MS effects could be stronger than in the dry snow conditions considered here. Developing such corrections, however, is beyond the scope of this study.

[21] Acknowledgments. This study was supported by NASA project NNX07AQ82G. A. Battaglia was supported by the Deutsche Forschungsgemeinschaft under the TOSCA project.

\section{References}

Battaglia, A., and C. Simmer (2008), How does multiple scattering affect the spaceborne W-band radar measurements at ranges close to and crossing the surface range, IEEE Trans. Geosci. Remote Sens., 46, 1644-1651.
Battaglia, A., M. O. Ajewole, and C. Simmer (2006), Evaluation of radar multiple scattering effects from a GPM perspective. Part I: Model description and validation, J. Appl. Meteorol. Climatol., 45, 1634-1647.

Battaglia, A., S. Kobayashi, S. Tanelli, C. Simmer, and E. Im (2008a), Multiple scattering effects in pulsed radar systems: An intercomparison study, J. Atmos. Oceanic Technol., 25, 1556-1567.

Battaglia, A., J. M. Haynes, and C. Simmer (2008b), Identifying multiplescattering-affected profiles in CloudSat observations over the oceans, J. Geophys. Res., 113, D00A17, doi:10.1029/2008JD009960.

Bouniol, D., A. Protat, A. Plana-Fattori, M. Giraud, J.-P. Vinson, and N. Grand (2008), Comparisons of airborne and spaceborne 95-GHZ radar reflectivities and evaluation of multiple scattering effects in spaceborne measurements, J. Atmos. Oceanic Technol., 25, 1983-1995.

Braham, R. R., Jr. (1990), Snow particle spectra in lake effect snows, J. Appl. Meteorol., 29, 200-207.

Haynes, J. M., T. S. L'Ecuyer, G. L. Stephens, S. D. Miller, C. Mitrescu, N. B. Wood, and S. Tanelli (2009), Rainfall retrieval over the ocean with spaceborne W-band radar, J. Geophys. Res., 114, D00A22, doi:10.1029/ 2008JD009973.

Korolev, A., and G. Isaac (2003), Roundness and aspect ratio of particles in ice clouds, J. Atmos. Sci., 60, 1795-1808.

Liu, G. (2004), Approximation of single scattering properties of ice and snow particles for high microwave frequencies, J. Atmos. Sci., 61, $2441-$ 2456.

Liu, G. (2008), Deriving snow cloud characteristics from CloudSat observations, J. Geophys. Res., 113, D00A09, doi:10.1029/2007JD009766.

Matrosov, S. Y. (2007a), Potential for attenuation-based estimations of rainfall rate from CloudSat, Geophys. Res. Lett., 34, L05817, doi:10.1029/ 2006GL029161.

Matrosov, S. Y. (2007b), Modeling backscatter properties of snowfall at millimeter wavelengths, J. Atmos. Sci., 64, 1727-1736.

Matrosov, S. Y., and A. J. Heymsfield (2008), Estimating ice content and extinction in precipitating cloud systems from CloudSat radar measurements, J. Geophys. Res., 113, D00A05, doi:10.1029/2007JD009633.

Matrosov, S. Y., A. J. Heymsfield, and Z. Wang (2005), Dual-frequency radar ratio of nonspherical atmospheric hydrometeors, Geophys. Res. Lett., 32, L13816, doi:10.1029/2005GL023210.

Matrosov, S. Y., K. A. Clark, and D. E. Kingsmill (2007), A polarimetric radar approach to identify rain, melting-layer, and snow regions for applying corrections to vertical profiles of reflectivity, J. Appl. Meteorol. Climatol., 46, 154-166.

Matrosov, S. Y., M. D. Shupe, and I. V. Djalalova (2008a), Snowfall retrievals using millimeter-wavelength cloud radars, J. Appl. Meteorol. Climatol., 47, 769-777.

Matrosov, S. Y., A. Battaglia, and P. Rodriguez (2008b), Effects of multiple scattering on attenuation based retrievals of stratiform rainfall from CloudSat, J. Atmos. Oceanic Technol., 25, 2199-2208.

Mitchell, D. L. (1988), Evolution of snow-size spectra in cyclonic storms. Part I: Snow growth by vapor deposition and aggregation, J. Atmos. Sci., $45,3431-3451$.

Mitchell, D. L., and A. J. Heymsfield (2005), Refinements in the treatment of ice particle terminal velocities, J. Atmos. Sci., 64, 1727-1736.

Tanelli, S., S. L. Durden, E. Im, K. S. Pak, D. Reinke, P. Partain, R. Marchand, and J. Haynes (2008), CloudSat's cloud profiling radar after 2 years in orbit: Performance, external calibration, and processing, IEEE Trans. Geosci. Remote Sens., 46, 3560-3573.

Woods, C. P., M. T. Stoelinga, and J. D. Locatelli (2008), Size spectra of snow particles measured in wintertime precipitation in the Pacific Northwest, J. Atmos. Sci., 65, 189-205.

A. Battaglia, Meteorological Institute, University of Bonn, Auf dem Hugel, 20, D- 53121 Bonn, Germany.

S. Y. Matrosov, Cooperative Institute for Research in Environmental Sciences, University of Colorado and NOAA Earth System Research Laboratory, 325 Broadway, Boulder, CO 80305, USA. (sergey.matrosov@ noaa.gov) 